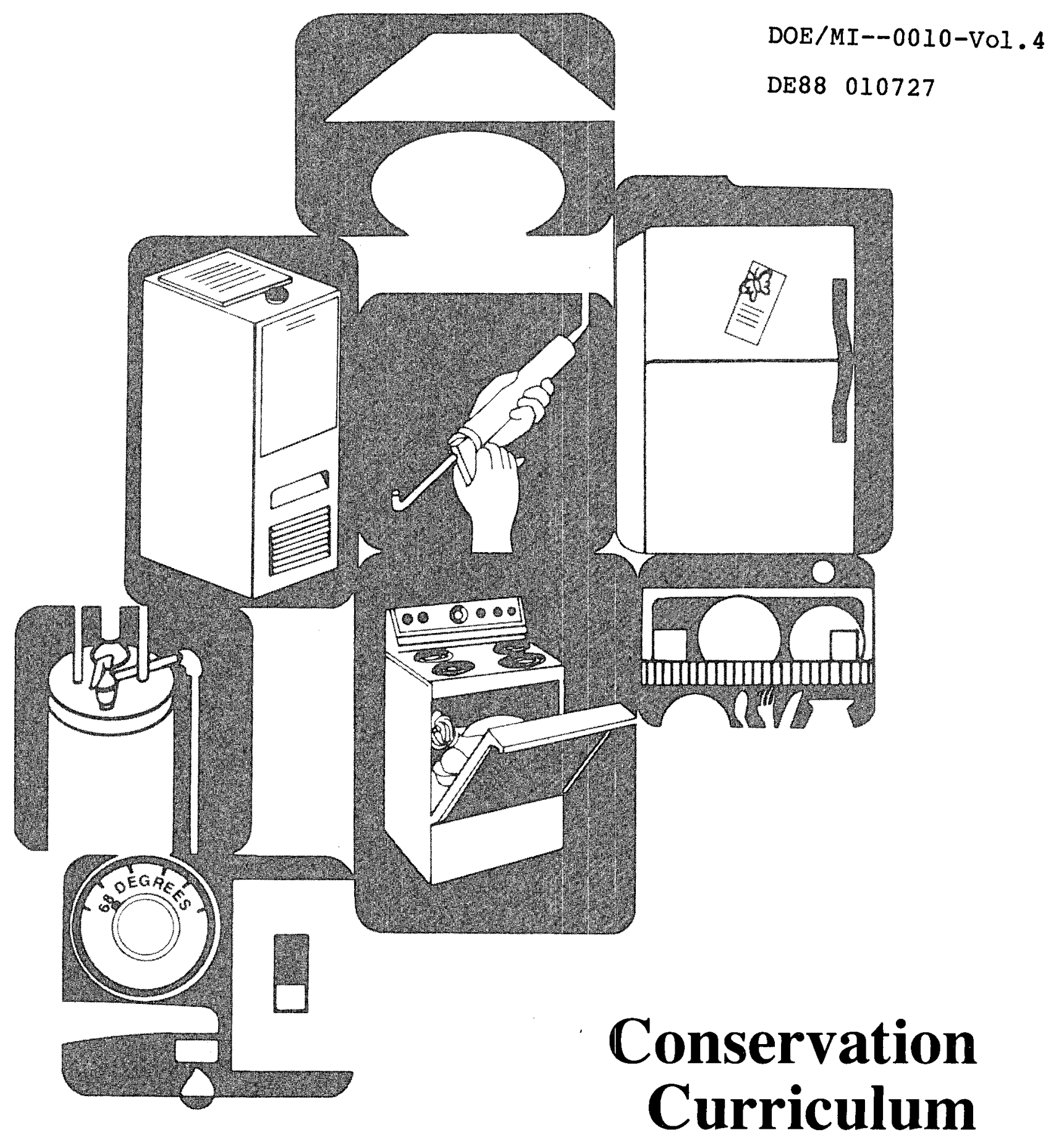

\title{
Guide for Public Housing Residents and Renters
}

Volume IV

Prepared by:

The Assignment Group

P.O. Box 1883

Rockville, Maryland 20850
U.S. Department of Energy

Office of Minority Economic Impact

Research and Education Division

Washington, DC 20585 


\section{DISCLAIMER}

This report was prepared as an account of work sponsored by an agency of the United States Government. Neither the United States Government nor any agency Thereof, nor any of their employees, makes any warranty, express or implied, or assumes any legal liability or responsibility for the accuracy, completeness, or usefulness of any information, apparatus, product, or process disclosed, or represents that its use would not infringe privately owned rights. Reference herein to any specific commercial product, process, or service by trade name, trademark, manufacturer, or otherwise does not necessarily constitute or imply its endorsement, recommendation, or favoring by the United States Government or any agency thereof. The views and opinions of authors expressed herein do not necessarily state or reflect those of the United States Government or any agency thereof. 


\section{DISCLAIMER}

Portions of this document may be illegible in electronic image products. Images are produced from the best available original document. 


\section{CONSERVATION CURRICULUM GUIDE}

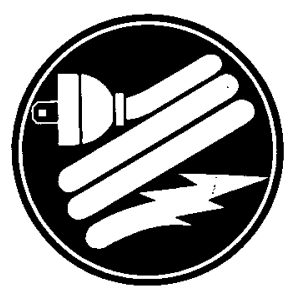

\section{INTRODUCTION}

Why saving energy is important in public housing:

Whether you pay your own heating and utility bills or they are paid by the Housing Authority, saving energy is important. It can help you stay warm, comfortable and healthy during the winter months.

This guide will show you how plugging up cracks and holes, wrapping up (insulating) and living wisely with energy will help you to save energy and be more comfortable.

\section{Explanation of "energy saving measures":}

Energy saving measures are those things you can do to stop losing heat to the outside - such as plugging up cracks in doors, windows, walls, and ceilings, and insulating your walls and attic.

\section{Explanation of "energy saving practices":}

Energy saving practices are low-cost or no-cost things you can do to use your appliances, heat, and air conditioning wisely. How you use your hot water, your refrigerator, or your thermostat can make a big difference in the amount of energy you use.

\section{Buying appliances wisely:}

From time to time, appliances must be replaced. From refrigerators to light bulbs, almost everything that uses energy has an energy saving model available. Because of lower operating costs, energy saving models are usually better buys, even if they cost more initially. The higher cost will be paid back to the purchaser through lower energy bills.

\section{(A) ENERGY SAVING MEASURES}

\section{TIGHTEN WINDOWS:}

A broken or loose-fitting window is a big energy waster and is often the cause of uncomfortable drafts in your home. Fortunately, there are a number of inexpensive and easy-to-install solutions:

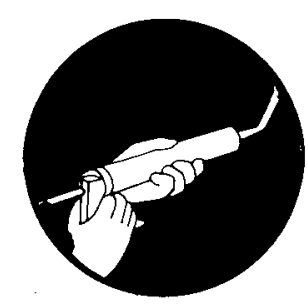

- Cracks in the windows should be.taped; any clear tape will do. Broken windows should be replaced. For a temporary repair, cover the broken glass with a heavy piece of cardboard and tape in place. Make sure all air leaks are taped over.

- Air leaks from loose-fitting windows can be stopped by caulking between the window frames and walls, both inside and outside if possible.

- Weatherstrip the moveable sash with inexpensive rope caulk or plastic or felt weatherstripping. The rope caulk is the least expensive to buy, but it will dry out in a year and must be removed each time the window is opened.

If you can't afford weatherstripping, place folded cloth or newspaper at the top, center, and bottom of the window. Close and lock the window to make a tight seal. 


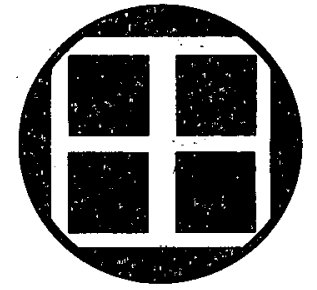

\section{INSULATE WINDOWS}

Windows also lose heat through the glass. You can reduce this heat loss by insulating your windows:

- Plastic which covers both the window and its frame stops air leaks and slows down heat transfer to the outside. This plastic can be applied to the inside window frame each year with tape, tacks, or staples. Leave one or two windows unsealed for ventilation.

- Insulated drapes, when tightly fitted, can provide greater insulation than plastic.

- Rigid interior shutters provide the same insulating value as the drapes, but are often less expensive. Panels of rigid insulation, such as polystyrene or fiberglass, can be cut to fit your windows, covered with a fire-retardant material, and finished attractively with paint, fabric, or wallpaper. Check with your hardware store.

\section{TIGHTEN DOORS}

Doors, like windows, can be big energy wasters. Many techniques for sealing doors are similar to those for windows:

- Caulk between the door frame and wall, both inside and outside.

- Weatherstrip where the door closes against the frame.

- Install a door sweep across the bottom edge of the door.

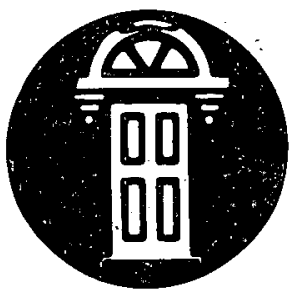

- A folded rug, blanket, or newspaper pushed up against the bottom of the door will also keep the cold from getting in.

- Unused doors to attics, outside porches, or unheated rooms can be covered completely with plastic, which can be easily torn away in an emergency.

\section{SEAL CRACKS AND HOLES IN WALLS}

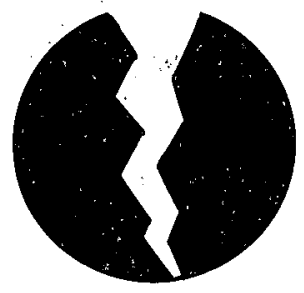

Although doors and windows can be the largest sources of air leaks in your apartment, small cracks and holes in the walls can add up to considerable heat loss as well.

- Tape small wall cracks, and cover large holes with heavy cardboard and tape.

- Install foam gaskets under light switch and outlet covers.

- Remove air conditioners from the windows in the fall, if possible. If not, cover the outside of the air conditioner with heavy plastic.

\section{SEAL CRACKS AND HOLES IN CEILINGS AND FLOORS}

Like walls, ceilings and floors often have many unnoticed passages for heat to escape and cold air to enter. These holes can be plugged easily and inexpensively:

- Tape or patch cracks or holes in plaster.

- Rugs on floors will help seal off drafts. If you still feel cold air coming in, roll up the rug and cover the floor with several layers of newspaper, then replace the rug.

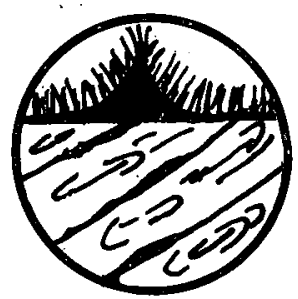




\section{TURN DOWN HOT WATER TEMPERATURE (TURN OFF IF GOING AWAY)}

Your hot water heater may be working harder than it needs to. If the temperature setting is too high, you are producing hotter water than you need. Generally a setting of 120 degrees $F$ is sufficient, but, if you have a dishwasher, you may need hotter water. Contact your landlord or maintenance person to check the thermostat setting and lower it, if needed.

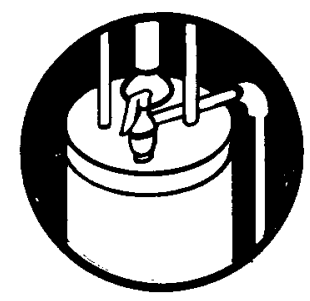

When you are away for more than two days, turn an electric water heater off; turn a gas heater to "pilot" or "stand-by".

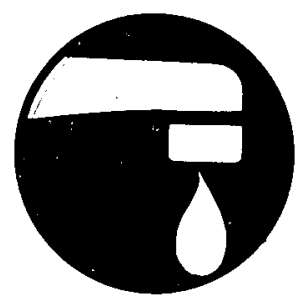

\section{REDUCE HOT WATER FLOW}

You can also save money and energy by cutting down on the amount of hot water you use. Much of the hot water that comes out of your tap goes down the drain without being useful. Here's how you can use less water:

- Install sink aerators and flow-restricting showerheads which let less water through but don't change its force. A sink aerator simply screws onto the end of your faucet and requires no special tools to install. A flow-restricting showerhead can reduce water use by up to $60 \%$ without reducing shower comfort.

- Repair leaky faucets. One leaking faucet can waste as much as 125 gallons of water a month, or 1500 gallons a year.

\section{REPLACE LIGHTBULBS WITH ENERGY-SAVING OR FLUORESCENT BULBS}

Although lighting may account for a relatively small amount of your energy use, you can reduce your electric bills somewhat and maintain the same lighting levels by making these simple changes:

- Replace standard incandescent lightbulbs with high efficiency bulbs. Although they

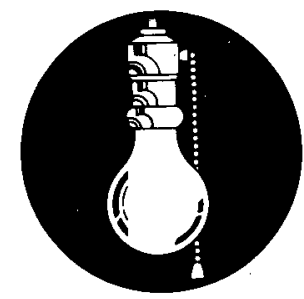
produce slightly less light, high efficiency bulbs last $2 \frac{1}{2}$ times longer and cost $10 \%$ less to operate.

- Replace standard incandescent bulbs with fluorscent bulbs which are now available for use in incandescent lamps. You can substitute a 44-watt fluorscent bulb for a 100-watt incandescent bulb.

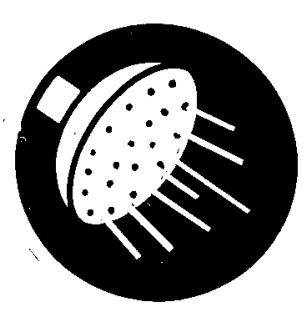

\section{(B) ENERGY SAVING PRACTICES}

\section{BATHING}

If you bathe four times a week, you can save about $\$ 40$ a year by taking five-minute showers with a flow-resticting showerhead, rather than taking tub baths.

When washing and shaving, fill the sink rather than letting the water run. Be sure to turn the faucets off completely.

\section{DISHWASHING}

If you rinse your dishes under running water, you are running money down the drain. Use a dishpan for rinsing. By dipping your dishes in clean rinsewater, rather than rinsing them under running water, you can save up to $\$ 120$ a year.

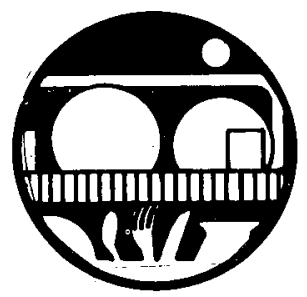




\section{CLOTHES WASHING}

The cost of running your washing machine depends on the amount of hot water it uses. Reduce the amount of hot water and save yourself some money. There are several ways of doing this without sacrificing the cleanliness of your wash:

- Wash items requiring hot water together. Wash other items in warm or cold water.

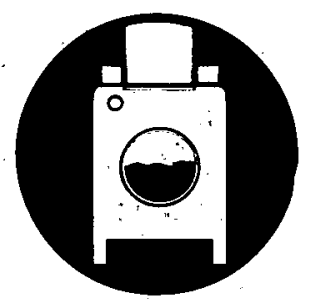

- Wash full loads where possible, but avoid overloading the machine.

- Use a cold rinse where possible.

- Pre-soak heavily soiled clothes.

\section{CLOTHES DRYING}

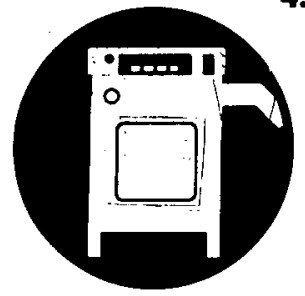

If you have a clothes dryer, here are some simple and economical practices:

- When possible, hang up your clothes to dry. If you have a porch, and it is permitted, put up a clothesline. Use an inexpensive portable drying rack for delicate clothes, sweaters, and small washloads. Not only will you save energy, but your clothes will last longer.

- Clean the lint filter after each load.

- Do not overdry your clothes. It wastes energy - and money - and is damaging to the fabrics.

- Dry full loads, but do not overload the dryer.

\section{HEATING}

By carefully controlling your thermostats and keeping the heaters and outlet vents free from obstructions, you can be more comfortable for less cost:

- Set your thermostat no higher then 68 degrees $F$ while at home, and 55 degrees while

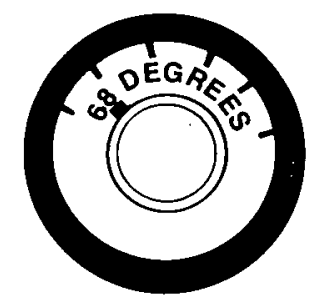
away.

- Reduce heat in rooms not used regularly. Close the doors and shut off the registers or heating units.

- Avoid blocking heating units with furniture or drapes.

- Do not place furniture in front of windows or in cold and drafty areas.

\section{AIR CONDITIONING}

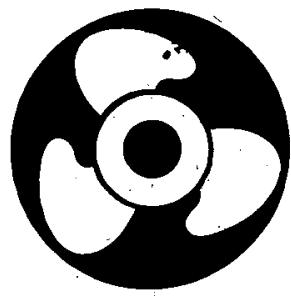

An air conditioner can be a great comfort on hot summer days, but also can be costly to run. Here are a few simple ways to keep costs to a minimum:

- Use window fans rather than the air conditioner as often as possible.

- Clean the filter regularly. It is plastic, and can be washed in warm, soapy water.

- Turn your air conditioner off while away.

- When shopping for a new air conditioner, look for the most energy efficient model to suit your space and price range. 


\section{REFRIGERATOR/FREEZER}

If your refrigerator is colder than 38 degrees $F$. or is not located or maintained properly, it is costing you money unneccessarily.

- Keep the temperature in your refrigerator at 38-40 degrees, the recommended temperature for food storage. The freezer temperature should be 0 degrees.

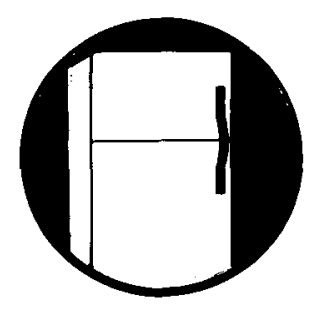

- Keep your refrigerator at least 3 inches away from the wall. If possible, locate it away from the stove and other heat sources.

- Dust the coils at the bottom or back of the refrigerator regularly. Clean coils allow air to circulate more freely and result in more efficient cooling.

- Check the door seal to be sure it is tight and in good condition. Close the door on a dollar bill, and then try to remove the bill. If it pulls out easily, the seal is not tight.

- Open the door as little as possible.

- Allow hot foods to cool before putting them in the refrigerator or freezer.

- Your freezer is most efficient when it is full. If you do not have enough frozen foods, fill the remaining space with trays of ice cubes.

- Do not allow more than $1 / 4$ inch of frost build-up. Defrost regularly to allow for better air circulation and more efficient cooling.

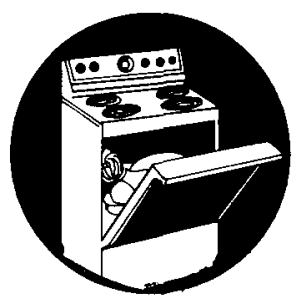

\section{STOVE/OVEN}

Whether you cook with electricity or gas, there are a number of kitchen habits you can develop to save energy:

- Use a pan that is close in size to your burner. The pan should have a flat bottom to allow for better heat transfer and a tight-fitting lid to cook food in less time and save energy.

- Turn off electric burners shortly before the recommended cooking time is completed. The residual heat will finish the cooking.

- Keep burner reflectors clean and shiny, so they will reflect more heat back into the pan.

- When possible, cook a double batch of food and freeze the extra portion for another meal.

- Use ceramic or glass cookware in the oven, and reduce the oven temperature by 25 degrees.

- Bake several dishes at the same time.

- Don't open the oven door to "take a peek" at what's cooking.

- Avoid pre-heating whenever possible. Meats will shrink less if put into a cold oven and allowed to heat up gradually. If pre-heating is necessary, pre-heat only 5-8 minutes.

Use smaller appliances - toaster \& broiler ovens, electric fry pans, crock pots, microwaves - whenever possible. 


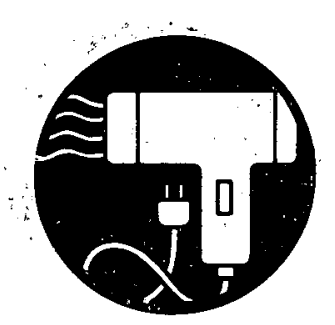

\section{LIGHTING \& SMALL APPLIANCES}

How you use lights and certain small appliances can make a difference in your electric bill:

- Use a small 4-watt nightlight rather than leaving the hallway light on.

- Turn off the lights whenever you leave the room - even if only for a short time.

- Use a timer to turn lights on and off for security when you are away from home.

- Towel and air dry your hair as much as possible. Running an electric hair dryer for 10 minutes costs the same as burning a 60 -watt bulb for three hours.

- The "instant on" feature of some television sets uses energy. When your TV is not in use, turn off this feature or unplug the set.

\section{BLINDS, SHADES, \& DRAPES}

Although window shades, drapes, curtains, and blinds don't use energy, there are ways in which you can use them to save energy. Used properly, they can reduce heat loss and drafts from your window frames. The closer they fit to the top, sides, and bottom of the window frames, the less cold air will be able to circulate from behind the windows and into the room.

\section{In Winter:}

- Close shades, drapes, and curtains at dusk, fitting them tightly against the bottom of the window.

- On sunny days, open shades, drapes, and curtains on southfacing windows to take advantage of "free" solar energy.

- Keep drapes and curtains from blocking radiators, registers, and heating units.

\section{In Summer:}

- Close shades, drapes, curtains and blinds to block direct sunlight and keep your apartment cooler. This will also keep your furniture from fading in the strong summer sunlight.

Since electric and gas bills can be an important factor in anyone's budget, it may be useful to identify the approximate costs of operating the appliances in your apartment. Feel free to call your local utility company and ask them to send you any information they may have on the operating costs and efficient use of household appliances. 